\title{
Procrastination and Delayed Assignment Submissions: Student and Faculty Perceptions of Late Point Policy and Grace within an Online Learning Environment
}

\author{
Beverly Santelli, Sarah N. Robertson, Elizabeth K. Larson, and Samia Humphrey \\ Grand Canyon University
}

\begin{abstract}
An exploratory study using a questionnaire was conducted among 597 full-time enrolled online students and 53 full-time online faculty teaching at a private university in the Southwest. Results are presented in frequency tables and participant feedback to compare differences and similarities of instructor and student perceptions of reasons for late assignment submission, late point policy, and leniency within an online learning environment. Differences in perception between student and faculty participants are noted. Further inquiry into the impact late assignment submissions, late point policies and instructor leniency have on student success rates, satisfaction, and persistence is warranted.
\end{abstract}

Keywords: late point policy, late submissions, faculty grace, procrastination, homework extension, assignment submission patterns, perception on leniency, online learning

Santelli, B., Robertson, S.N., Larson, E.K., \& Humphrey, S. (2020). Procrastination and delayed assignment submissions: Student and faculty perceptions of late point policy and grace within an online learning environment. Online Learning, 24(3), 35-49.

10.24059/olj.v24i3.2302

\section{Procrastination and Delayed Assignment Submissions: Student and Faculty Perceptions of Late Point Policy and Grace within an Online Learning Environment}

As of 2018, one-third of college students were taking at least one online class (Ruth, 2018). Online education has experienced dramatic growth in recent decades thanks to advantages such as flexibility, convenience, and access to a classroom worldwide (Bowers \& Kumar, 2015). However, the online learning environment can have a significant impact on a student's ability or desire to complete a task on time. There are challenges online students face, in addition to the typical challenges students tend to encounter while in college. The online learning environment can elicit feelings of isolation and disconnectedness (Bowers \& Kumar, 2015). Arasaratnam-Smith and Northce (2017) also contend that it can be difficult to create a sense of community for online students. Furthermore, it can be challenging for instructors to maintain proximity and a strong social presence within an online asynchronous environment (Dyer, Aroz, \& Larson, 2018). This is 


\section{Procrastination and Delayed Assignment Submissions: \\ Student and Faculty Perceptions of Late Point Policy and Grace within an Online Learning Environment}

important as a sense of community and an in increase in instructor social presence can help aid in student retention (Sorensen \& Donovan, 2017). Late point policies to help encourage students to submit on time have become a topic of discussion in higher education as late assignment submissions can be an early warning sign of student nonpersistence.

\section{Review of Related Literature}

\section{Procrastination and Late Assignment Submission}

Late assignments submissions are sometimes generalized as procrastination. Procrastination can be defined as the intentional delay of a task (Nordby, Klingsieck, \& Svartdal, 2017). The delay can come at any point of the action, whether it is at the beginning of the task or at its completion. Although procrastination is intentional, it may not be consciously labeled by the learner as procrastination. Procrastination, particularly for college students, is a ubiquitous phenomenon. Roughly, $70 \%$ of college students identified themselves as procrastinators (You, 2015). While procrastination might be seen as a harmless trait, one of its main results are late assignments.

Falkner and Falkner (2012) found that assignment submission patterns could be an indicator for identifying at-risk students and increased rate of course withdrawals at an institution. Several studies show a correlation between student procrastination and academic performance (Nordby et al., 2017). Procrastination can lead to missed classes, assignments, and result in lower grades. Additionally, the quality and accuracy of work can be reduced due to the pressure associated with completing an assignment on a crunched timeline (Kim \& Seo, 2015). In addition, procrastination tendencies are linked to poor goal achievement and lower achievements (Akran, et al., 2019).

Yilmaz (2017) found that students in an online environment procrastinated more on assignment submissions compared to their traditional face-to-face counterparts. This is understandable as life events can affect one's schoolwork. Due to its autonomous nature, the online learning environment places a high demand of self-regulation from students (Klingsieck Fries, Horz, \& Hofer, 2012). This is significant as Kara (2015) found that self-regulation is an important trait found in effective learners. Additionally, studies have shown that procrastinators delay or are not as engaged in participation due to a lack of self-regulation (You, 2015). Further, "Procrastinators in e-learning tended to perform worse than non-procrastinators but also that the negative relationship between procrastination and achievement in the e-learning environment was stronger than that in the traditional learning environment" (You, 2015, p. 66). In addition, students who post late into an online class have a significantly higher rate of being unsuccessful overall as the onset of procrastination formed an early habit (McElroy \& Lubich, 2013).

\section{Individual Factors for Late Submissions}

"Research over the past four decades has amply demonstrated that individual factors significantly contribute to the procrastination problem" (Nordby et al., 2017, p. 493). These individual factors vary from student to student; however, family and work obligations can often cause additional challenges (Kara, Erdogdu, Kokoç \& Cagiltay, 2019). Online learners are typically older by 10 to 15 years ( 25 to 40 years of age) than the traditional, young adult student who is taking face-to-face classes (17 to 25) (Kuo \& Belland, 2016). Since many adult learners work full time, choosing to go to school online is perceived as far more convenient than the 
alternative of a face-to-face classroom (Kuo \& Belland, 2016). Difficulties juggling expectations at work, family responsibilities, personal time, and schoolwork often arise for nontraditional students. Student motivation also may fluctuate during their enrollment and may be impacted by situational factors, such as financial problems, family distress, employment status, etc. (Newhouse \& Cerniak, 2016). Some online adult students feel that their instructors are inflexible with deadlines and not supportive for the additional responsibilities that are presented (Dumais, Rizzuto, Cleary, \& Dowden, 2013). With this juggling, can come reduced prioritization on assignment deadlines and thus procrastination on assignment completion and submission may feel justified by the student. Lin (2016) argues that females in particular are facing additional barriers as adult learners enrolled in college due to commitments of multiple roles and insufficient social and family support.

Another reason why college students procrastinate may be due to an assignment's characteristics. Students are given many study-related tasks, which represent an important environmental context for student delay in submissions (Nordby et al., 2017). Task aversion (degree of unpleasantness, perceptions of boring or uninteresting a student associates with a task), is a high predictor for student delay in starting, working on, and finishing assignments (Nordby et al., 2017). Additionally, level of task difficulty is associated with procrastination. Interestingly enough, the level of difficulty on both ends of the spectrum (either too challenging or not challenging enough) can lead to procrastination. As Nordby et al. (2017) noted, the more difficult the task, the more students tend to procrastinate; at the same time, the easier a task was, the more likely students were to perceive the task to be boring or uninteresting. In addition, dispositional barriers, such as fear of failure and insecurities can often be linked to factors such as relationships with instructors (Shepard \& Nelson, 2012 as cited in Osam, Bergman, \& Cumberland, 2017). Furthermore, the guilt associated with avoiding necessary tasks can lead to individual's placing a greater importance on alternate activities, thus strengthening procrastination behaviors (Kaftan \& Freund, 2019).

\section{Faculty Considerations}

Teacher effectiveness, or lack thereof, can have a significant impact on timely assignment completion (Nordby et al., 2017). Corkin, Shirley, Wolters, and Wiesner (2014) found that procrastination and instructor organization had an inverse relationship. This was in large part because effective instructors provided a classroom climate that made it easier for students to organize and plan their work. Further, instructors who set clear and fair deadlines reduced a student's likelihood to procrastinate as opposed to students whose deadlines are self-imposed (Nordby et al., 2017). In addition to classroom management issues, a lack of teaching skill can affect academic procrastination. In Patrzek, Grunschel, and Fries's (2012) study, school counselors reported that poor coaching and teaching skills provide students with insufficient direction. Couple that with a faculty member who feels "absent" to students in the classroom, and it can further disconnect students from their class and their assignments as instructor presence and lack of social interaction negatively affects student persistence and retention (Bower \& Kumar, 2015).

Traditional face-to-face faculty perceptions on leniency for late assignment submissions are varied. Some instructors do not feel it is fair to give some students leniency while their classmates worked hard to submit their assignments on time (Patton, 2000). While Kostal, Kuncel, and Sackett (2016) suggest that grade inflation over the years may be related to the overall pressure of pleasing the student in a shift to a more student-centered approach. Consequently, this potential stress of balancing student scores with high satisfaction surveys could lead to more lenient grading 
and potentially more acceptance of late student submissions. Note, the perception of leniency by faculty who teach primarily online courses is a gap in literature.

Some universities allow faculty independence but request that no faculty member is stricter than the university's stated late point policy. Thus, faculty may choose to deduct less per day the assignment is late or grant students permission (grace) to submit assignments late without late point deductions. With this being the case, changes in how faculty implement the late point policy and whether or not they provide "grace" on assignments from one course to the next could confuse students on their own personal assignment completion and submission practices (Patton, 2000). Instructors are regularly confronted with moral or ethical issues that do not have an easy solution (Dukewich, 2016). One such moral dilemma centers on the acceptance of late assignment submissions. This is because every instructor at the collegiate level will have to make decisions that center on whether or not they should accept late assignment submissions, and whether to grade the work any differently from those that were submitted on time (Boisvert, Garcia, Giersch, Strickland, \& Whitaker, 2015). To support faculty and students alike, many universities have parameters on what late work can or cannot be accepted, as well as any repercussions for late submissions. However, the acceptance of late assignments at the collegiate level is still somewhat of a controversial topic among faculty.

\section{Late Submission Policy}

The purpose of a late submission policy is to provide transparency and remove any ambiguity of an instructor's expectations. However, navigating the late policy can be confusing for students as Boisvert et al., (2015) postulated the number of late submission policies at one university were as numerous as there were instructors. While there are a vast number of late policies, the most common policy is to allow leniency in assignment deadlines, but instructors will apply a small percentage penalty on the late submission (Tyler, Preveler, \& Cutler, 2017). For example, instructors might have a $10 \%$ per day penalty for assignments submitted after their due date.

Additionally, there are policies that can reflect the opposite ends of the spectrum. For example, instructors might adopt draconian policies that do not allow any leniency, thus prohibiting the submission of late work. While this policy might be beneficial for instructors, particularly for those with a large class size, students can perceive it to be overly strict and unfair (Boisvert et al., 2015). On the opposite end of the spectrum, instructors might implement a no penalty policy for late submissions. With a no penalty policy, late submissions are accepted without a penalty or requirement of documentation. Boisvert et al. (2015) acknowledged that a no penalty policy might be effective in upper division courses that have smaller class sizes but caution its use in lower division courses as it can cause numerous assignments submitted after their deadline and extra work for the instructor.

Another way to prevent late assignment submissions is through the implementation of a predetermined, university-wide, late point policy. The policy informs instructors and warns students on how many points are deducted per day an assignment is submitted past the due date. It is uncertain whether this reduces the likelihood of procrastination but may motivate students to submit what they have completed by the deadline. This also provides students with a consistent policy to rely on from one course to the next, no matter the instructor they are assigned. Students who do not miss an assignment deadline may also be more likely to continue with a course. In fact, students who submit assignments early tend to have higher grades (Jones \& Blankenship, 2019). 
Boisvert et al. (2015) identified five key criteria that should be taken into consideration in order to create an effective late assignment submission policy: the delivery of course materials, consideration of student needs, preparation for the future, grading that reflects mastery, and value of time spent on grading and assignment. The right balance between these key priorities will change from course to course, or even on the type of assignment. For example, Tyler et al. (2017) noted that computer science assignments are prone to unexpected complications such as semantic errors that require a long time to resolve.

While there is much research available on self-regulation and procrastination of online students, there is not as much information available on late point policies that instructors use for this population of college level students and the varying levels of perception on flexibility regarding this concern. What do online students think about a university late point policy and changes in instructor implementation of said policy? And in what ways do late policies influence self-regulation in online courses?

\section{Methods}

\section{Research Questions and Study Design}

This quantitative, exploratory study set out to answer the following research questions:

1. What are online student and online faculty perceptions of when leniency should be considered by faculty?

2. What are online student and online faculty perceptions of a university-wide late assignment policy?

3. What are online student and online faculty perceptions how strictly faculty adhere to the university-wide policy?

A three-part questionnaire was developed through SurveyMonkey to collect both student and faculty participant data. Part one collected informed consent and had participants differentiate whether they were students or faculty, part two focused on questions framed to gain student perceptions, and part three focused on questions framed to gain faculty perceptions. Based on participant responses in part one, they were either directed out of the study (as in they did not provide informed consent), or they were then automatically directed to either the student or faculty section of the questionnaire. This tool was designed to address the aforementioned research questions. With this in mind, most questions between the faculty and student sections of the survey were aligned with one another. For example, question 10 of the faculty section and question 8 of the student section both read: "It is important to allow instructors to designate their own late point policy as long as it is not stricter than the $10 \%$ per day University policy." Some questions however varied in efforts to learn more about the participant and/or their perspectives. Faculty variation example: "How many years have you been teaching online for the university? (Round up to the nearest whole number)." Student variation example: "I would be more likely to submit assignments on time if GCU's late assignment policy was strictly enforced in every course." The three-part questionnaire is available to researchers for review and use upon request.

Eight questions used a five-point Likert scale with one representing strongly agree and five representing strongly disagree. Below each of these questions, a comment box was provided. The questionnaire was created by the researchers and this study was the first time the survey was deployed. Researchers wanted to provide participants with an opportunity to comment on and/or 
explain any response they desire. Responses within the comments section were not required. Due to this, they were not analyzed as qualitative data but rather as anecdotal commentary to the quantitative data. Additionally, one question within the survey requested that participants "Identify scenarios in which leniency is appropriate. Check all that apply." This question provided four options with check boxes to the left of each option. Participants were able to check any and all they felt applied to the statement. A copy of the survey is available upon request.

\section{Population and Participant Demographics}

The population consisted of both full-time, online faculty who have been employed with a private university in the Southwest for a minimum of six months and students who are enrolled into an online program at the same university. Approximately 187 employees were full-time online faculty within the University during the Fall 2019 semester (University Administration, personal communication, 2019). Approximately, 80,000 students were enrolled into an online program within the Fall 2019 semester (University Administration, personal communication, 2019).

A recruitment email sent by faculty services notified faculty of the opportunity to participate in the study and provided a link to complete informed consent and part three of the questionnaire. Of the 187 full-time, online faculty, 61 volunteered to complete the questionnaire. After cleaning and screening, 53 faculty participants fully completed all questions within part three of the questionnaire and could be utilized within the study. Ages ranged from 25 to 64 years of age with a majority of faculty participants, $45.3 \%$ between the ages of 35 to 44 . Furthermore, $9.4 \%$ were 25 to 34 years of age, $26.4 \%$ were between 45 to 54 years of age, and $18.9 \%$ were between 55 to 64 years of age. Of the 53 faculty participants, $62.7 \%$ were female and $37.7 \%$ were male. Faculty participants taught across most colleges with 25 participants in humanities and social sciences, 13 in education, 1 in nursing, 6 in business, 2 in doctoral studies, and 6 in theology. Two colleges, performing arts and science, technology, engineering and math did not have any faculty participants to represent their departments.

Volunteer faculty participants posted a recruitment note for students within the online course discussion forum in the last week of class. The note provided an overview of the study and a link to complete the informed consent and questionnaire. Out of roughly 4,000 online students in the sample, 608 volunteered to participate in the study. After cleaning and screening, 597 student participants completed all questions and could be used within data analysis. The ages of students ranged from 18 to 64, with a majority of online student participants between the ages of 25 to 33 at $40.2 \%$ while $20.1 \%$ were 18 to $24,24.6 \%$ were 34 to $44,12.7 \%$ were 45 to 54 and $2.4 \%$ were 55 to 64 .

Reflective of the faculty participant demographics, a majority, $75.4 \%$ of student participants were female. Student participants varied in the level of degree program they were enrolled in, though a majority, $89.3 \%$ were enrolled in an undergraduate program, $9.4 \%$ within a master's level program, and $1.3 \%$ in a doctoral program. Of the 597 student participants, $24 \%$ reported they were currently in their first course within their program. All eight colleges were represented by student participants with $22.3 \%$ in humanities and social sciences, $31.5 \%$ within education, $10.2 \%$ in nursing, $17.8 \%$ in college of business, $0.5 \%$ in fine arts, $15.9 \%$ in science, technology, engineering and math, $0.8 \%$ in doctoral studies, and $1.0 \%$ in theology. 


\section{Data Collection and Analysis Methods}

Site and IRB approval for no more than minimal risks were granted prior to data collection. An acknowledgement was provided in part one of the questionnaire to inform participants of the study's intent to maintain participant anonymity. No identifying information was collected at any point within the study. Informed consent was completed by a "click to confirm" button at the bottom of part and page one of the questionnaire. Data collection for both faculty and student samples lasted one month during the Fall 2019 semester. Analysis was completed through the export of SurveyMonkey questionnaire responses into SPSS. After cleaning and screening, frequency tables for responses of each question within the questionnaire were compiled as initial results. Since there was a vast difference in the quantity of faculty versus students who completed the survey in full ( 53 faculty and 597 students), frequency histograms are provided as figures below and frequency percentages for each set of criteria (strongly agree, agree, neither agree nor disagree, disagree, strongly disagree) were reported within the written results to assist in comparing the two groups.

\section{Results and Discussion}

Four histograms, Figures 1-4, were created from selected frequency tables to provide the most comprehensive takeaways from the data collected for student and faculty perceptions regarding late point penalties and leniency. These histograms also address the study's targeted research questions.

A notable difference was found when comparing student perceptions of instructor grace with the late policy and instructor perceptions of leniency with the late policy. Of the 597 students surveyed, $31.2 \%$ agreed that their teachers strictly adhere to a late point deduction of $10 \%$ per day with no exceptions, while $52 \%$ of instructors strongly disagreed with adhering to a late point deduction of $10 \%$ per day with no exceptions. Students may be under the impression that an instructor will uphold the late point policy while instructors themselves plan to show grace. It is important to note here, that of the 597 student participants surveyed, 49 made a specific disclaimer within the open response section below the questions that they have never submitted an assignment late. Though 49 chose to make a disclaimer about not submitting an assignment late in the past, there may be more student participants who have yet to be late on an assignment submission. Some student perceptions then were based on what they believed would be the case, not necessarily what they had experienced to be the case. Figure 1 below displays a histogram of participant responses to the statement: "Faculty strictly adhere to $10 \%$ deduction per day with no exceptions." 


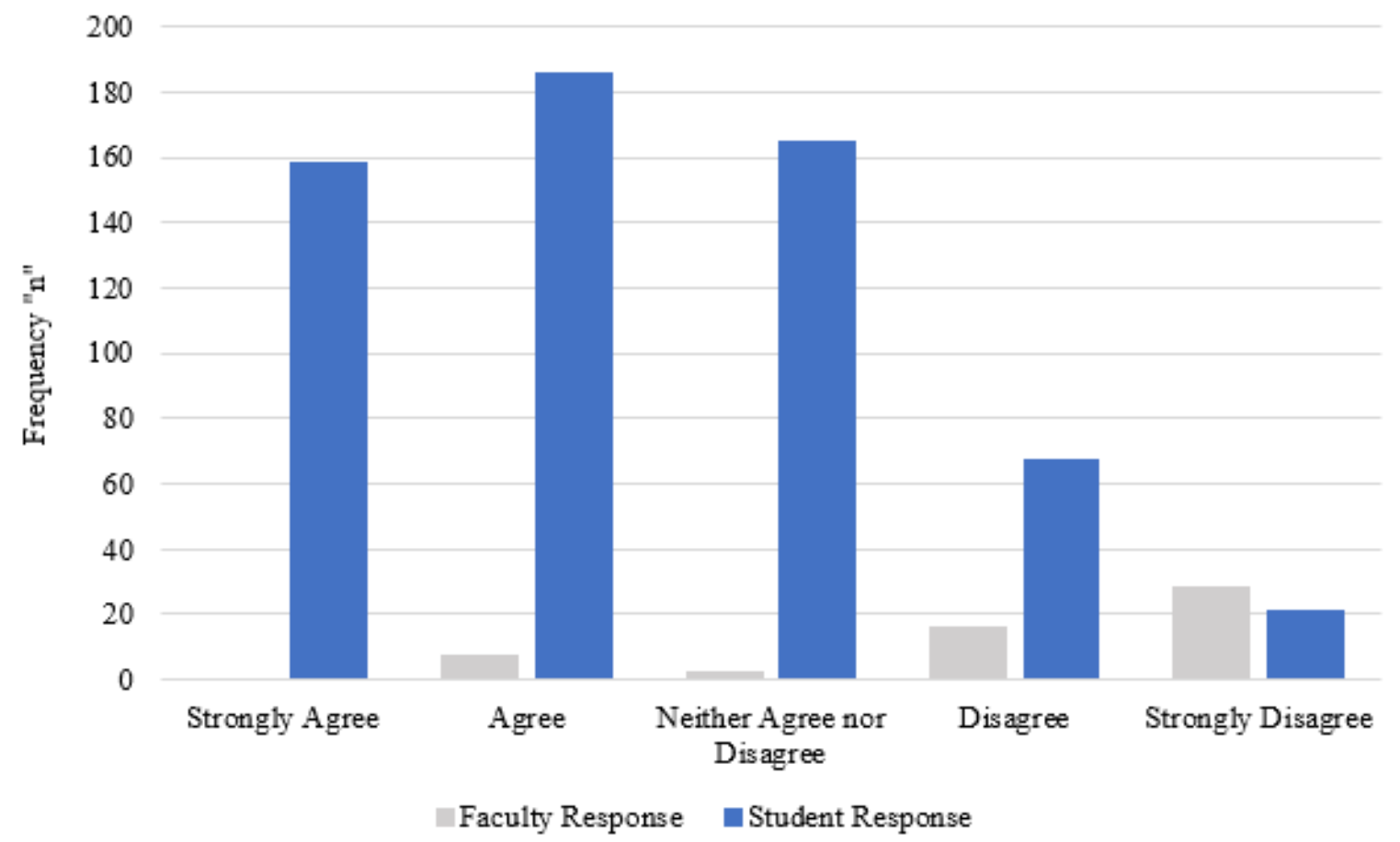

Figure 1. Faculty strictly adhere to $10 \%$ deduction per day with no exceptions.

Student and faculty participant perceptions were more closely aligned when it came to whether a deduction of $10 \%$ per day was an effective late policy for an institution to have in place, with $64.1 \%$ of faculty strongly agreeing or agreeing and $69.9 \%$ of students strongly agreeing or agreeing. It is important to note that these comparisons are not based on equal sample sizes. Figure 2 below displays the frequencies of participant responses to the statement: "A deduction of $10 \%$ per day is an effective late policy for an institution to have in place." Some open response reasons were provided by participants such as "This teaches the students of the consequence of missing a deadline," from one faculty participant. "Especially for a seven-week course," came from another and, "I agree that it is good to have in place; however, I believe it is better that it is to be used at the instructor's discretion," came from a third. Student participants strongly agreed with follow up open responses such as: "There is plenty of time to get assignments in if you are using time management wisely." "I believe this to be highly motivating in the completing of assignments on time." "This gives students a chance to submit a late assignment with a deduction instead of receiving a failing grade."

As mentioned previously, some online adult students feel their instructors are not flexible with deadlines and are not taking onto consideration the additional responsibilities of said students (Deumais et al., 2013). Interestingly, though a smaller percentage, more student participants, 9.7\% than faculty participants, $3.8 \%$ disagreed in viewing the $10 \%$ per day late deduction policy as effective with open-ended follow up responses such as: "Punishment is not effective late policy to have in place, instead, the drive to receive points as a student is enough driving force to complete assignment." "Circumstances should be taken into consideration." "There should be a late penalty, I don't agree with $10 \%$. Most people who choose online school did so because of a job, family or other obligations. Sometimes it is difficult to meet the Wed., Fri., Sun. deadline but $10 \%$ is too big of a hit and you find yourself pushing that 11:59 PM deadline at times." Only one faculty participant who disagreed provided an open-ended response stating, "Depending on the situation." 


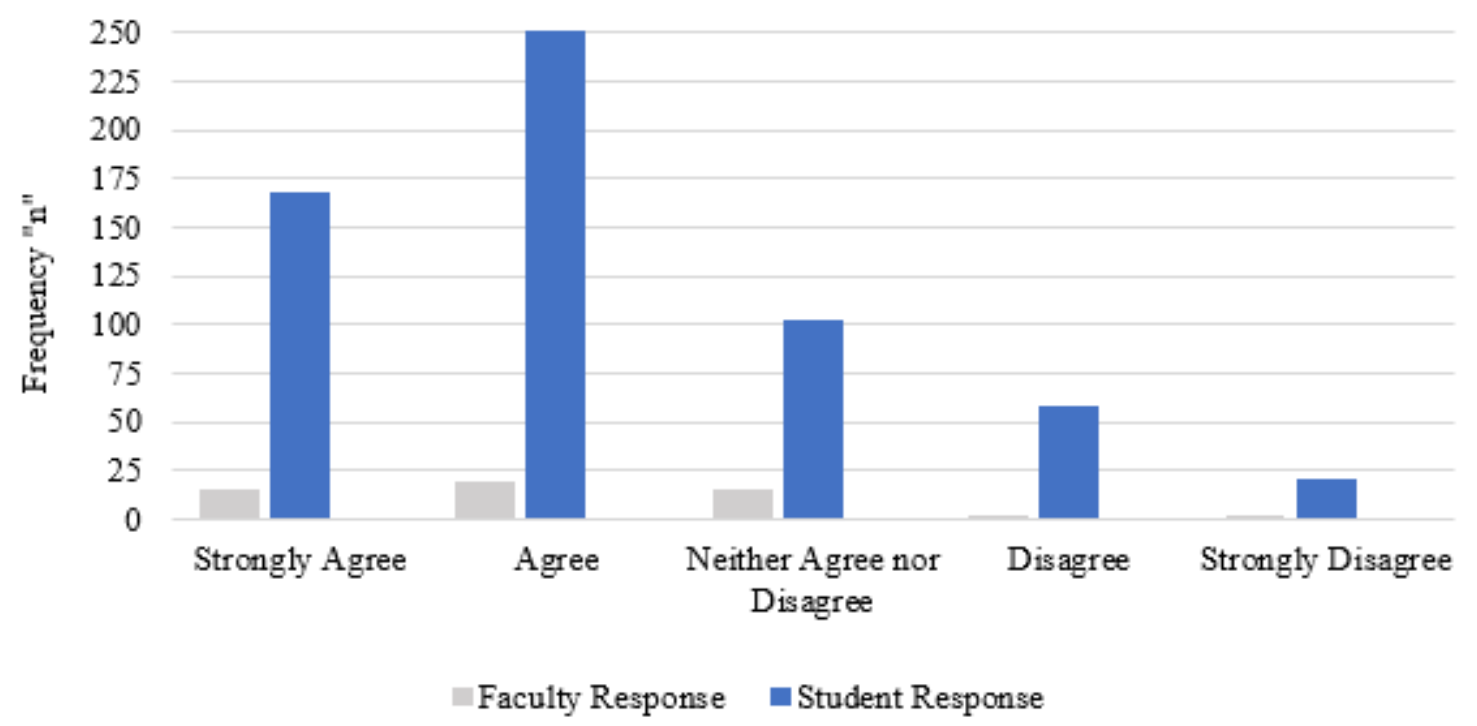

Figure 2. A deduction of $10 \%$ per day is an effective late policy for an institution to have in place.

Another area where student and faculty participant perceptions were in somewhat alignment was when asked if the $10 \%$ per day late point deduction was too lenient. Figure 3 below displays a histogram of participant responses to the statement: A deduction of $10 \%$ per day is too lenient and should be stricter. Of the 53 instructors surveyed, $45 \%$ disagreed while $47 \%$ of the 597 student participants disagreed. The Likert category with the biggest difference in frequency of responses was between faculty who strongly disagreed at $43 \%$ versus the $31 \%$ of students who strongly disagreed. Figure 3 below provides a histogram of the frequency rates for responses and is how percentages above were generated. Some student open responses can help to explain why there may have been more students who agreed and/or were neutral than the faculty: "I never feel free to be late at all, and I feel like the allowance tempts me to procrastinate." "Depends how often it is happening." "Only if it is for first time offenders of late policy and it should increase with the increase of times the student is consistently late." It may be an important reminder here that 49 student participants reported within open responses that they had never submitted an assignment late.

In comparing student and faculty perceptions of situations in which instructor leniency with the late policy is appropriate, faculty participants had less "tolerance" for submission of the wrong document in comparison to student participant perspectives when it came to providing late submission leniency. However, this could be attributed with experience. While all instructor participants may have had this happen, students who participated may not have ever submitted late for this reason. See Figure 4 below for frequency histogram of both student participant and faculty participant responses. 
Procrastination and Delayed Assignment Submissions:

Student and Faculty Perceptions of Late Point Policy and Grace within an Online Learning Environment

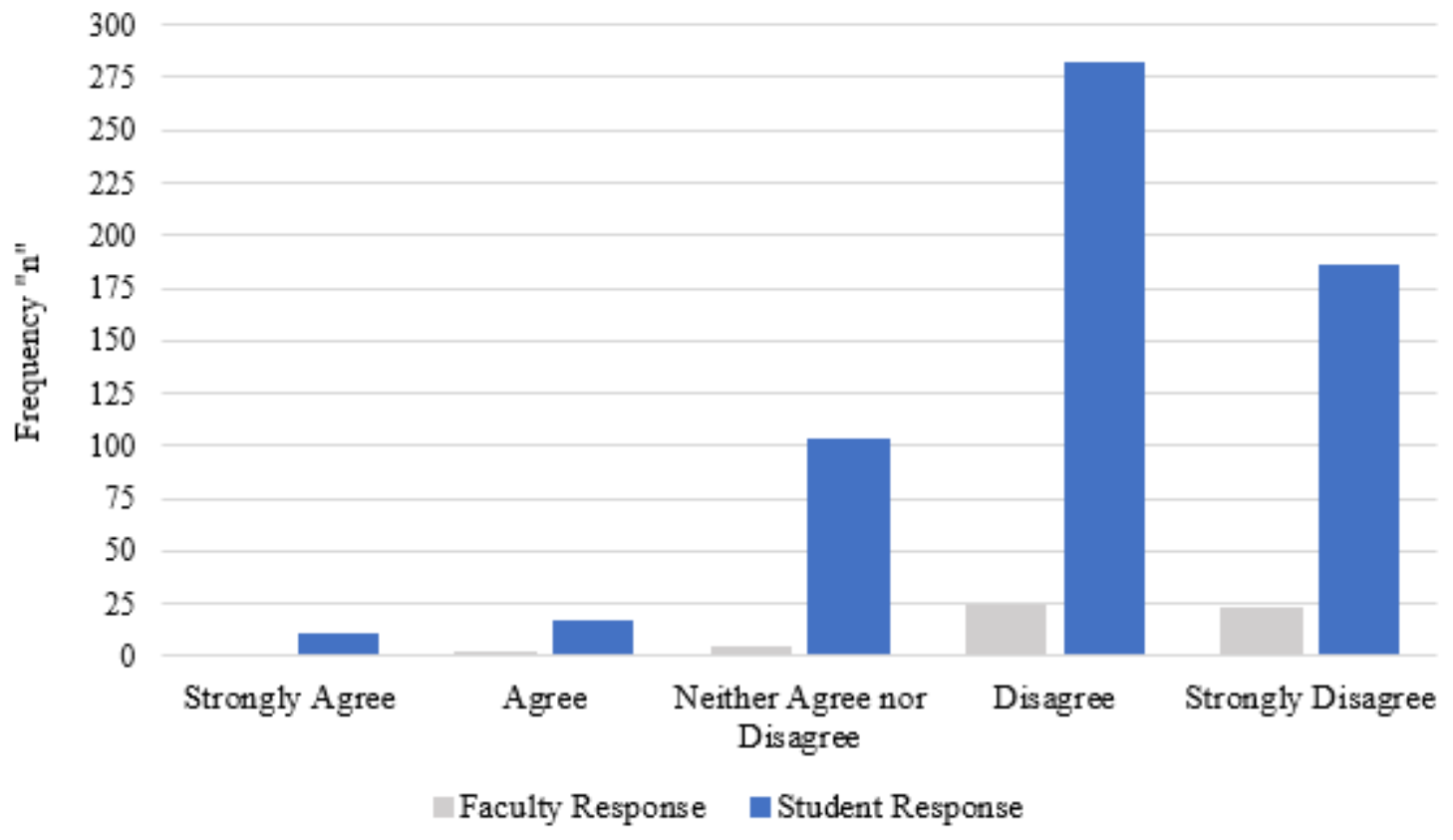

Figure 3. A deduction of $10 \%$ per day is too lenient and should be stricter.

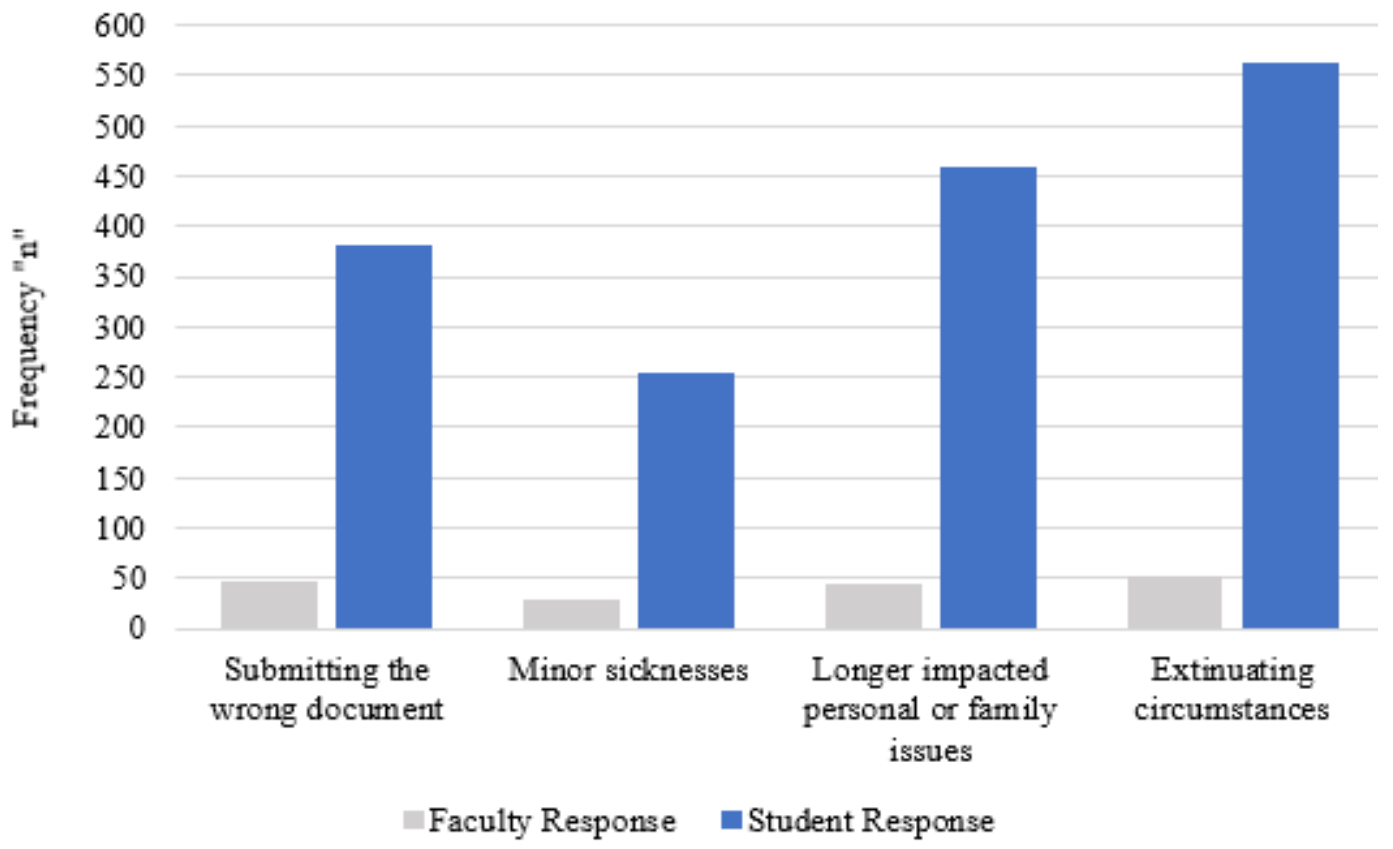

Figure 4. Identify scenarios in which leniency is appropriate. 


\section{Conclusion}

This exploratory study has shed some light on both faculty and student perceptions and interpretations of instructor and institutional late policies, specific to a distance learning environment in which students are more prone to procrastinate (Yilmaz, 2017). There were areas of agreement as well as areas where student and faculty perceptions did not align. It is interesting to note that there were more similarities than differences between faculty and student perceptions of leniency. For the most part, the two groups of participants were aligned in agreement on the effectiveness and fairness of an institutional late policy of 10 percent per day and scenarios in which leniency is appropriate. There was a divergence in perceptions between faculty members and students in the need for strict adherence to a late policy that provides point deductions per day. This difference in perception may be attributed to a variety of factors, including teaching philosophy, student expectations, or if student participants have previously requested leniency on a late policy.

Adopting a late policy that includes a late penalty may serve as a dual purpose: providing motivation for students to turn in assignments on time, as well as holding them accountable (Nordby et al., 2017). Depending on the institution, faculty may or may not have flexibility on the late point policy for their class. Based on the wide array of faculty perceptions on how much of a deduction should occur for late submissions, it is important for faculty members to designate their own late point policy. This flexibility is important as long as it is not perceived to be severe, which for this study was more than a 10 percent point deduction per day.

Though one question asked student participants to identify the reasons for their past late submissions, there was no question within the questionnaire that directly asked student participants if they have ever submitted any assignment late. This is a limitation to the study. In mulling over the results, it was noted that 49 student participants had at some point within open responses of the survey noted that they had never submitted an assignment late. Not all participants utilized the open response sections, thus there may be more student participants who had not experienced/worked through a late submission during their online program. It could be that more student participants are within this category as volunteer participants may be more involved in their classes and have a greater connection to the content. It could be then that student participants are not generalizable to the entire student population. For example, would results differ if data was sorted to only include responses from students who had submitted an assignment late? This could be an opportunity for additional research. It may be of interest in future studies to also ask faculty participants a similar question as to whether they had ever submitted an assignment late while they were students. Responses may provide clues as to how they frame their perception as well and could possibly begin to explain some of the discrepancies between student and faculty perceptions in how strictly they adhere to the late policy and in instances where leniency may be acceptable.

The survey used in this study was available for all 187 full time faculty. While 53 faculty did volunteer to participate, it is important to note that not all colleges represented equally if at all. In fact, there were no faculty participants representing the colleges of science, technology, engineering, and math or the fine arts. The majority of the faculty participants were from the college of humanities and social sciences. Further research that includes more faculty participation across all areas of study in the survey is recommended in order to assess any differences in faculty and late submission practices between the varying programs of study. The same recommendation can be applied to recruiting additional fine arts and STEM, and more student participants. 
While there are limitations, this study provides in-depth insight into online faculty and student perceptions on current known late policies in higher education. Replication of this study should be straightforward. One change needed in the questionnaires is to include responses "I do not know" or "I have never had a late assignment" at the end of each question for student participants, instead of "neither agree nor disagree." This change will help provide students who might not have had to ask for leniency a more accurate option to answer each question.

Future research studies on faculty and student perceptions of late policy leniency should include questions that are designed to identify the ideal late point policy, if students have felt the need to request leniency on the late policy in the past, and if so, how many times this roughly occurred per course. Further inquiry into how students feel the late point policy and/or faculty grace impacts them and whether they see the late point policy as a technique to combat against procrastination would be of interest and could be accomplished through a case study. Additional research could also work to compare differences in late point policy perceptions of full-time faculty who only teach online courses for one institution and those who have an online adjunct role at one or even across multiple schools. 


\section{References}

Akram, A., Fu, C., Li, Y., Javed, M. Y., Lin, R., Jiang, Y., \& Tang, Y. (2019). Predicting students' academic procrastination in blended learning course using homework submission data. IEEE Access, Access, IEEE, 7, 102487-102498. https://doi.org/10.1109/access.2019.2930867

Arasaratnam-Smith, L. A., \& Northcote, M. (2017). Community in online higher education: Challenges and opportunities. Electronic Journal of e-Learning, 15(2), 188-198. http://www.ejel.org/volume15/issue2/p188

Bowers, J., \& Kumar, P. (2015). Students' perceptions of teaching and social presence: A comparative analysis of face-to-face and online learning environments. International Journal of Web-Based Learning and Teaching Technologies (IJWLTT), 10(1), 27-44. https://dblp.org/rec/journals/ijwltt/BowersK15

Boisvert, D., Garcia, W., Giersch, J., Strickland, J., \& Whitaker, B. E. (2015). Late work and late adds. Students' Pathways to Success: A Faculty Guide, 65-72. https://omp.uncc.edu/library/catalog/book/2

Corkin, D. M., Shirley, L. Y., Wolters, C. A., \& Wiesner, M. (2014). The role of the college classroom climate on academic procrastination. Learning and Individual Differences, 32, 294-303. https://www-sciencedirectcom.lopes.idm.oclc.org/science/article/pii/S1041608014000727?via\%3Dihub

Dyer, T., Aroz, J., \& Larson, E. (2018). Proximity in the online classroom: Engagement, relationships, and personalization. Journal of Instructional Research, 7, 108-118. https://eric.ed.gov/?id=EJ1188336

Dukewich, K. R., \& Wood, S. (2016). “Can I have a grade bump?” The contextual variables and ethical ideologies that inform everyday dilemmas in teaching. Collected Essays on Learning and Teaching, 9, 97-110. https://eric.ed.gov/?id=EJ1104491

Dumais, S. A., Rizzuto, T. E., Cleary, J., \& Dowden, L. (2013). Stressors and supports for adult online learners: Comparing first-and continuing-generation college students. American Journal of Distance Education, 27(2), 100-110. https://doi.org/10.1080/08923647.2013.783265

Falkner, N. J., \& Falkner, K. E. (2012). A fast measure for identifying at-risk students in computer science. In Proceedings of the ninth annual international conference on International computing education research (pp. 55-62). ACM. https://dl.acm.org/doi/10.1145/2361276.2361288

Feild, J. (2015). Improving student performance using nudge analytics. In Proceedings of the 8th International Conference on Educational Data Mining (pp. 464-467). https://files.eric.ed.gov/fulltext/ED560905.pdf

Jones, I. S., \& Blankenship, D. C. (2019). The effect of procrastination on academic performance of online students at a Hispanic serving institution. Journal of Business Diversity, 19(2), 1015. https://articlegateway.com/index.php/JBD/article/view/2053 
Kaftan, O. J., \& Freund, A. M. (2019). A motivational perspective on academic procrastination: Goal focus affects how students perceive activities while procrastinating. Motivation Science, 5(2), 135-156. https://psycnet-apa-org.lopes.idm.oclc.org/record/2018-32060-001?doi=1

Kara, M., Erdogdu, F., Kokoç, M., \& Cagiltay, K. (2019). Challenges faced by adult learners in online distance education: A literature review. Open Praxis, 11(1), 5-22. https://eric.ed.gov/?id=EJ1213733

Kim, K. R., \& Seo, E. H. (2015). The relationship between procrastination and academic performance: A meta-analysis. Personality and Individual Differences, 82, 26-33. https://www-sciencedirectcom.lopes.idm.oclc.org/science/article/pii/S0191886915001610?via\%3Dihub

Klingsieck, K. B., Fries, S., Horz, C., \& Hofer, M. (2012). Procrastination in a distance university setting. Distance Education, 33(3), 295-310. https://www.tandfonline.com/doi/full/10.1080/01587919.2012.723165

Kostal, J. W., Kuncel, N. R., \& Sackett, P. R. (2016). Grade inflation marches on: Grade increases from the 1990s to 2000s. Educational Measurement: Issues \& Practice, 35(1), 1120. https://onlinelibrary.wiley.com/doi/abs/10.1111/emip.12077

Kuo, Y.-C., \& Belland, B. R. (2016). An exploratory study of adult learners' perceptions of online learning: Minority students in continuing education. Educational Technology Research and Development, 64(4), 661-680. https://link.springer.com/article/10.1007/s11423-016-9442-9

Lin, X. (2016). Barriers and challenges of female adult students enrolled in higher education: A literature review. Higher Education Studies, 6(2), 119-126. https://files.eric.ed.gov/fulltext/EJ1101356.pdf

Litchfield, J. M., \& Matteis, M. (2016). Faculty experiences with technology, millennials versus baby boomers. Online Journal of Nursing Informatics, 20(1), 6-1. https://www.researchgate.net/publication/310510564_Faculty_experiences_with_technology millennials versus baby boomers

McElroy, B. W., \& Lubich, B. (2013). Predictors of course outcomes: early indicators of delay in online classrooms. Distance Education, 34(1), 84-96. https://eric.ed.gov/?id=EJ1005247

Nordby, K., Klingsieck, K., \& Svartdal, F. (2017). Do procrastination-friendly environments make students delay unnecessarily? Social Psychology of Education: An International Journal, 20(3), 491-512. https://link.springer.com/article/10.1007/s11218-017-9386-x

Newhouse, N. K., \& Cerniak, J. (2016). Student success factors in graduate psychology professional programs. Online Learning, 20(1), 70-91. http://dx.doi.org/10.24059/olj.v20i1.585

Osam, E. K., Bergman, M., \& Cumberland, D. M. (2017). An integrative literature review on the barriers impacting adult learners' return to college. Adult Learning, (2), 54. https://journals.sagepub.com/doi/full/10.1177/1045159516658013

Patton, M. A. (2000). The importance of being flexible with assignment deadlines. Higher Education in Europe, 25(3), 417-423. https://www.tandfonline.com/doi/abs/10.1080/713669270 
Patrzek, J., Grunschel, C., \& Fries, S. (2012). Academic procrastination: The perspective of university counsellors. International Journal for the Advancement of Counselling, 34(3), 185-201. https://scinapse.io/papers/2074269256

Ruth, S. (2018). Faculty opposition to online learning: Challenges and opportunities. International Journal of Technology in Teaching \& Learning, 14(1), 12-24. https://files.eric.ed.gov/fulltext/EJ1211994.pdf

Sorensen, C., \& Donovan, J. (2017). An examination of factors that impact the retention of online students at a for-profit university. Online Learning, 21(3), 206-221.

Tyler, J., Peveler, M., \& Cutler, B. (2017). A flexible late day policy reduces stress and improves learning. The 2017 ACM SIGCSE Technical Symposium, 718. https://doi.org/10.1145/3017680.3022439

Yilmaz, M. B. (2017). The relation between academic procrastination of university students and their assignment and exam performances: The situation in distance and face-to-face learning environments. Journal of Education and Training Studies, 5(9), 146-157. https://www.researchgate.net/publication/319189539_The_Relation_between_Academic_Pro crastination_of_University_Students_and Their_Assignment_and Exam_Performances_The Situation in Distance and Face-to-Face Learning_Environments

You, J. W. (2015). Examining the effect of academic procrastination on achievement using LMS data in e-learning. Educational Technology \& Society, 18(3), 64-74.

https://eric.ed.gov/?id=EJ1070043 